\title{
Assessment of Laparoscopically Harvested Omental Flap Used in Immediate Reconstruction in Breast Cancer Cases Eligible for Breast Conservative Surgery
}

\author{
MOHAMED S. EL-KOTAMY, M.Sc.; WALID Y. ELSHERPINY, M.D.; AYMAN M. ELSAKKA, M.D.; \\ HOSSAM R. MOUSSA, M.D.; MOHAMED A. MELEES, M.D. and AHMED A. DARWISH, M.D.
}

The Department of General Surgery, Faculty of Medicine, Tanta University, Egypt

\begin{abstract}
Background and Purpose: Breast conservative surgery is considered a standard surgical modality for treatment of early breast cancer. Omental pedicled flap is used for volume replacement after breast conservative surgery.

Aim of Study: The aim of this study was to assess the fate of laparoscopically harvested omental flap used in immediate reconstruction in breast cancer cases eligible for breast conservative surgery.
\end{abstract}

Patients and Methods: Ten female patients were included in this retrospective study which was conducted at The Surgical Oncology Unit, Department of General Surgery, Tanta University Hospitals, from June 2016 to July 2018. Every patient was subjected to mammography with complementary ultrasonography, Doppler ultrasound and Tru-cut needle biopsy from the omental flap and histopathology with different stains.

Results: Nodules were detected in $40 \%$ of cases which were proved to be benign in nature by Histopathology. Doppler revealed that two cases had partial infarction and degeneration of the omental flap. Histopathology revealed minimal inflammatory reaction, extensive fat necrosis and dense fibrosis in $50 \%$ of the studied cases. Vasculitis was detected in $30 \%$ of the studied cases. No recurrence of malignancy could be detected over the follow-up period. With CD31, various degrees of neovascularization were detected in the omental flap, mild in $20 \%$ of cases, moderate in $40 \%$ of cases and severe in $40 \%$ of cases. With CD8, T-Killer cells were found mild in $50 \%$ of cases and moderate in $40 \%$ of cases. CD44 detected presence of stem cells in $20 \%$ of cases.

Conclusion: The laparoscopically harvested omental flap had a promising oncological safety during the follow up. In spite of the fibrosis and nodulation found, no change was observed in the shape or contour of the breast. The inflammatory reaction and enhanced local immunity by the omentum is not studied as a possible preventive factor for recurrence. Vasculitis, angiogenesis and the presence of stem cells are not studied as a possible potentiating factor for recurrence of

Correspondence to: Dr. Mohamed S. El-Kotamy, The Department of General Surgery, Faculty of Medicine, Tanta University, Egypt breast cancer. So, long term follow-up is essential to see whether the omental flap could be a barrier against recurrence or it may enhance it.

Key Words: Breast cancer - Breast conservative surgery Omental flap.

\section{Introduction}

BREAST conservative surgery is considered the treatment of choice in early breast cancer $[1,2]$ Some studies have proved that immediate breast reconstruction is better than delayed reconstruction both aesthetically and functionally [3] .

Pure autologous tissue reconstruction is more desirable because of its durability, better appearance, softness, warmth, avoidance of implantrelated complications, and resistance to the effect of postoperative irradiation $[4,5]$. The use of the omental flap for breast cancer was first described by Kiricuta in 1963 [6]. More than a decade later, Arnold et al described a one-stage reconstruction of the breast using a transposed greater omentum. [7] Saltz et al., were the first to describe the laparoscopically harvested the omental flap for repair of soft tissue defects in 1993 [8]. A few years later, Costa et al., described the laparoscopically harvested omental flap for breast reconstruction and its use in the treatment of Poland syndrome in 1998 [9].

Recently investigators have shown that the omentum can be activated in the presence of foreign bodies. Once activated, the thin sheet like organ enlarges in size and mass wherein the new cells are predominantly non-fat stromal cells $[10,11]$ These stromal cells are a rich source of growth factors like fibroblast growth factor (FGB) and vascular endothelial growth factor (VEGF) and 
express adult stem cell markers including SDF-1a, CXCR4, WT-1, as well as pluripotent embryonic stem cell markers; Nanog, Oct-4, and SSEA-1 $[10,12,13]$. Data suggests that the omentum contains the potent ability of tissue regeneration and may be useful for treatment of various types of diseases involving tissue damages [14]. In this study we aimed to assess the fate of laparoscopically harvested omental flap used in immediate reconstruction in breast cancer cases eligible for breast conservative surgery.

\section{Patients and Methods}

This is a retrospective study including 10 female patients with breast cancer eligible for breast conservative surgery. It was conducted at The Surgical Oncology Unit, Department of General Surgery, Tanta University Hospitals. The duration of this study was 26 months, started from the ${ }^{\text {st }}$ of June 2016 to the 31 st of July 2018. They were operated on for local excision of breast cancer with immediate reconstruction of the breast with pedicled omental flap harvested with laparoscope. Every patient was called upon at least 6 months after finishing chemoradiotherapy. So the follow-up period ranged from 6 to 12 months. This study was approved by the ethics committee of our institution; informed consent was obtained from all patients after full explanation of the procedure. It was approved by the Research Ethical Committee, Faculty of Medicine, Tanta University.

\section{Patients selection criteria:}

Inclusion criterion:

Female patients eligible for breast conservative surgery with immediate breast reconstruction with volume replacement using laparoscopically harvested omental flap.

\section{Exclusion criteria:}

Patients with graft necrosis, patients with local recurrence and patients with soft tissue or bone metastasis.

Every patient in this study was subjected to the following:

\section{1- History taking:}

Complete history taking with emphasizing on breast complains in details:

- Personal data and reproductive history.

- Complaint: Breast lump, pain, axillary swelling, nipple discharge ... etc.

- Positive family history of breast cancer.

- Concomitant medical or surgical problems.
2- Clinical examination:

\section{General examination:}

- For presence of incisional hernia.

- To exclude soft tissue or bone metastasis.

\section{Breast examination including:}

- Breast contour, skin, nipple areola complex and symmetry.

- Breast mass (number, size, site, multiplicity and fixation).

- Any nipple discharge.

- Axilla and ipsilateral arm.

- Contralateral breast and axilla.

\section{3- Investigational studies:}

a- Laboratory investigations:

Relevant laboratory workup:

- Complete blood count.

- Coagulation profile (bleeding time, clotting time, prothrombin activity).

- Liver function tests as ALT, AST and alkaline phosphatase.

- Tumor markers (CEA, CA 15.3).

b- Imaging investigations:

- Mammography with complementary ultrasonography of the breast to assess the density of the breast and the omental flap, presence of any masses, calcifications and the axillary lymph nodes.

- Doppler ultrasound of the breast to assess the vascularity of the omental flap.

c- Histopathological investigation:

- Tru-Cut needle biopsy taken from every patient for Histopathological study, different stains were used in the study:

1- Conventional stains (H\&E) in every case.

2- Special stains:

a- P63 to prove the presence of sclerosing adenosis.

b- CD44 to prove the presence of stem cells.

c- CD8 to prove the presence of T-Killer cells.

d- CD31 to prove the presence of neovascularization.

\section{Statistical analysis:}

The collected data were organized, tabulated and statistically analyzed using SPSS version 25 (Statistical Package for Social Studies) created by IBM, Illinois, Chicago, USA. We used descriptive statistics, where data were expressed as number and percentage. 


\section{Results}

This study included 10 patients who underwent immediate breast reconstruction with volume replacement using laparoscopically harvested omental flap following breast conservative surgery and were followed-up from June 2016 to July 2018 at least 6 months following chemoradiotherapy. The ages of the studied patients ranged from 26 to 72 years old, with mean age $44.7 \pm 12.21$.

Regarding mammography with complementary ultrasonography, $40 \%$ of cases had mixed fatty glandular density, $20 \%$ were fatty, $20 \%$ were micronodular, whereas $20 \%$ were mixed fibrofatty. No masses were detected in $50 \%$ of the studied cases. No calcification was detected in any case during the follow up period. One case had a benign looking cyst. Nodules were detected in $40 \%$ of cases which were proved to be benign in nature by Tru-Cut needle biopsy and Histopathology.

By using Doppler, most cases showed normal vascularity of the omental flap, these were $80 \%$ of the studied cases. Two cases revealed partial infarction and degeneration of the omental flap, mostly due to the radiotherapy effect postoperatively. Histopathological examination of these 2 cases revealed fat necrosis and fibrosis with no recurrence.

Histopathological exam detected various degrees of inflammatory reaction, mostly was minimal in 50\% of the studied cases as shown in Table (1). Fig. (1) shows infiltration of the fat tissue by lymphocytes, macrophages and plasma cells. Fat necrosis was obvious in the omental flap. It was detected to be extensive in $50 \%$ of the studied cases as shown in Table (2), Fig. (2) shows an example of moderate fat necrosis in one of the studied cases.

The degree of fibrosis detected was mostly dense during the follow-up period in 50\% of the studied cases as shown in Table (3), Fig. (3) shows replacement of the fatty tissue of the omental flap by collagen fibers in one of the cases. Vasculitis was detected in $30 \%$ of the studied cases, most probably due to the effect of radiotherapy postoperatively, Fig. (4) shows an example of vasculitis in one of the cases.

No recurrence of malignancy could be detected in any of the studied cases over the follow-up period. CD31, an indicator for vasculo-endothelial cells, detection was somehow related to the degree of fibrosis found in histopathology, various degrees of neovascularization developed in the omental flap after implantation, found to be mild in $20 \%$ of cases, moderate in $40 \%$ of cases and severe in $40 \%$ of cases, possibly by the angiogenetic factors of the omentum, Fig. (5) shows neovascularization detected in one of the cases. CD8, an indicator of the presence of T-Killer cells, percentages was somehow related to the degree of inflammatory reaction found, mild presence was found in 50\% of cases, moderate presence was found in $40 \%$ of cases and severe presence was found in $10 \%$ of cases, Fig. (6) shows the detection of T-Killer cells in one of the cases. CD44, an indicator for stem cells, was found in $20 \%$ of cases, Fig. (7) shows the CD44 stain in two cases.

Table (1): Inflammatory reaction in histopathological samples.

\begin{tabular}{lll}
\hline \multirow{2}{*}{ Interpretation } & \multicolumn{2}{c}{$\begin{array}{c}\text { Inflammatory reaction in } \\
\text { histopathology }\end{array}$} \\
\cline { 2 - 3 } & No. & $\%$ \\
\hline Minimal & 5 & 50 \\
Mild & 2 & 20 \\
Moderate & 2 & 20 \\
Severe & 1 & 10 \\
& & 100 \\
\hline Total & 10 &
\end{tabular}

Table (2): Fat necrosis in histopathological samples of studied patients.

\begin{tabular}{lll}
\hline \multirow{2}{*}{ Interpretation } & \multicolumn{2}{c}{$\begin{array}{c}\text { Fat necrosis in } \\
\text { Histopathology }\end{array}$} \\
\cline { 2 - 3 } & No. & $\%$ \\
\hline Mild & 2 & 20 \\
Moderate & 3 & 30 \\
Extensive & 5 & 50 \\
& & 100 \\
\hline Total & 10 &
\end{tabular}

Table (3): Fibrosis in histopathological samples of studied patients.

\begin{tabular}{lcc}
\hline \multirow{2}{*}{ Interpretation } & \multicolumn{2}{c}{$\begin{array}{c}\text { Fibrosis in } \\
\text { Histopathology }\end{array}$} \\
\cline { 2 - 3 } & No. & $\%$ \\
\hline Mild & 3 & 30 \\
Dense & 5 & 50 \\
Keloid & 2 & 20 \\
& & 100 \\
\hline Total & 10 &
\end{tabular}




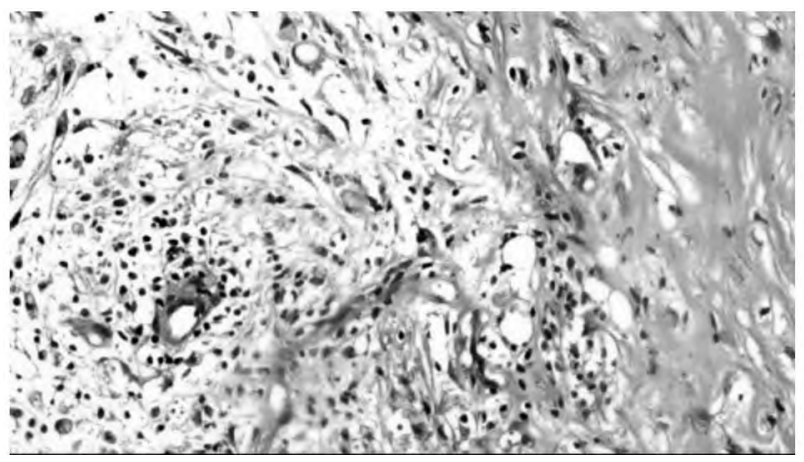

Fig. (1): Moderate inflammatory reaction in one of the cases by $\mathrm{H} \& \mathrm{E}$.

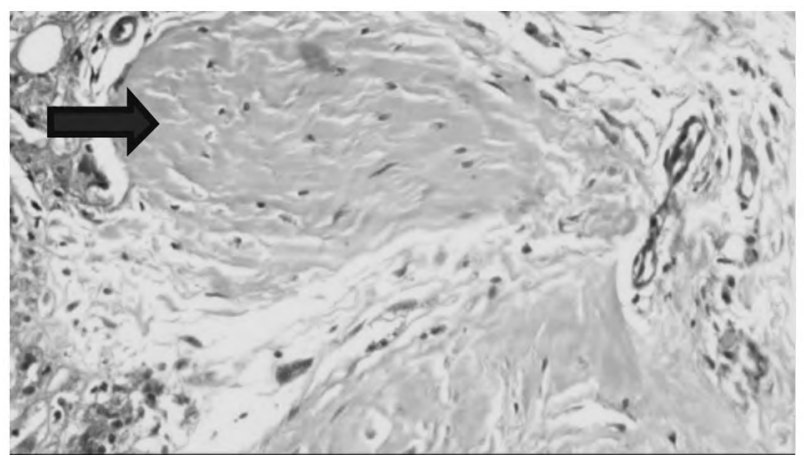

Fig. (3): Dense fibrosis in one of the cases by H\&E.

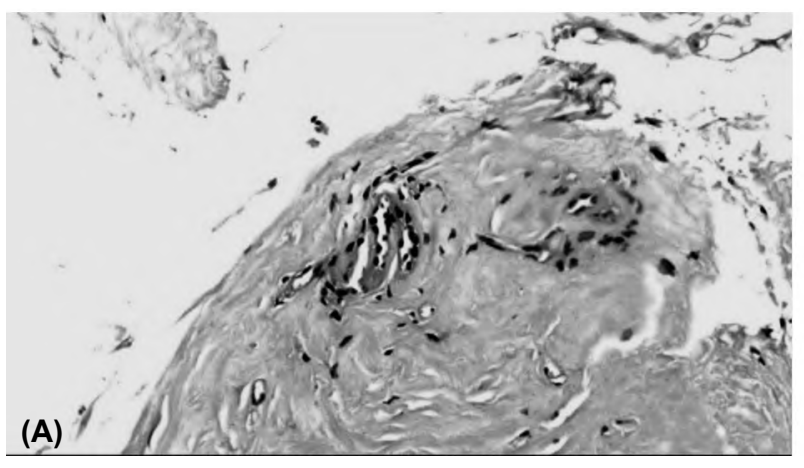

Fig. (5): Neovascularization detected in one of the cases, (a) X40 and (b) X100.

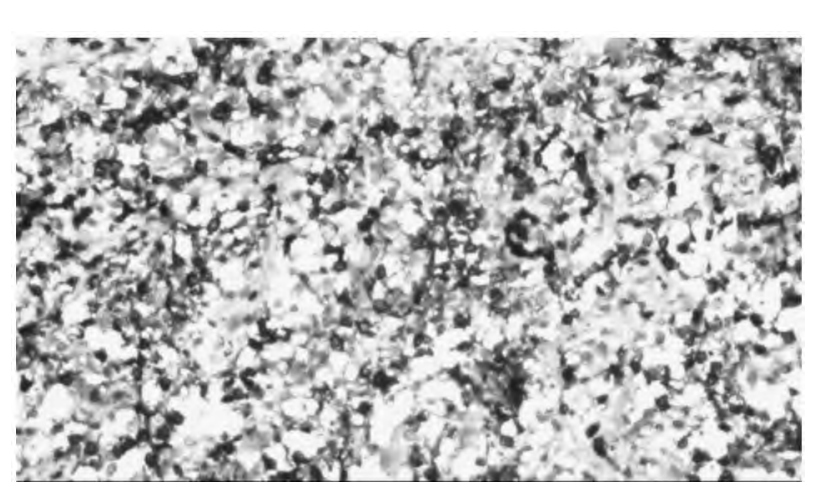

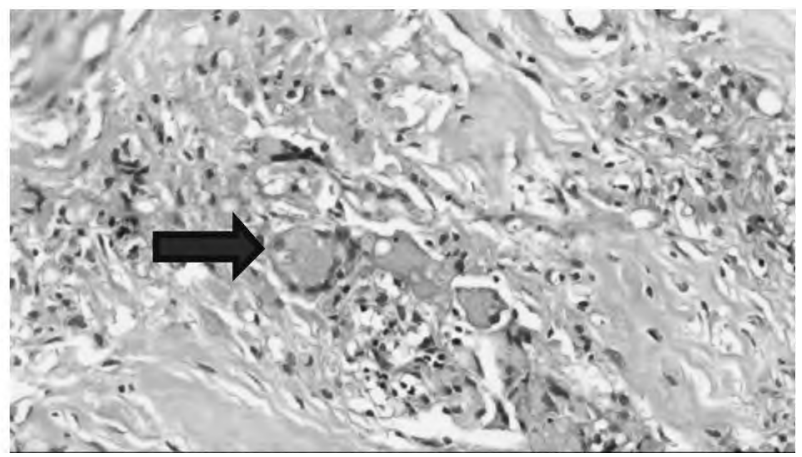

Fig. (2): Moderate fat necrosis in one of the cases by H\&E.

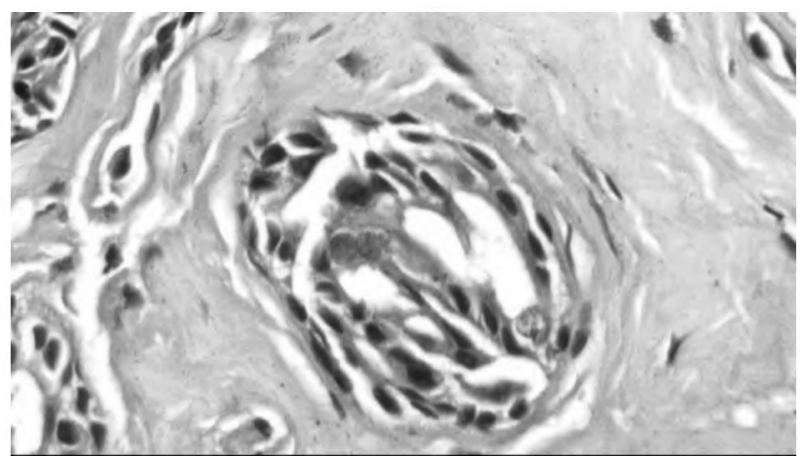

Fig. (4): Vasculitis with endothelial proliferation in one of the cases by $H \& E$.

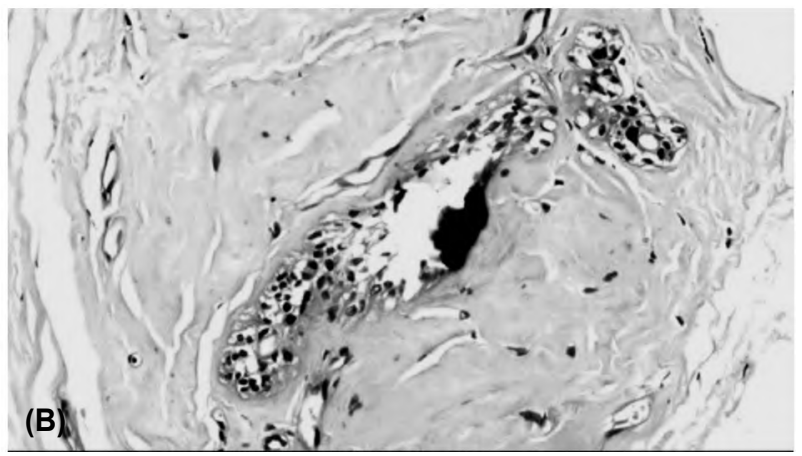

Fig. (5): Neovascularization detected in one of the cases, (a) X40 and (b) X100.

Fig. (6): The detection of T-Killer cells. 

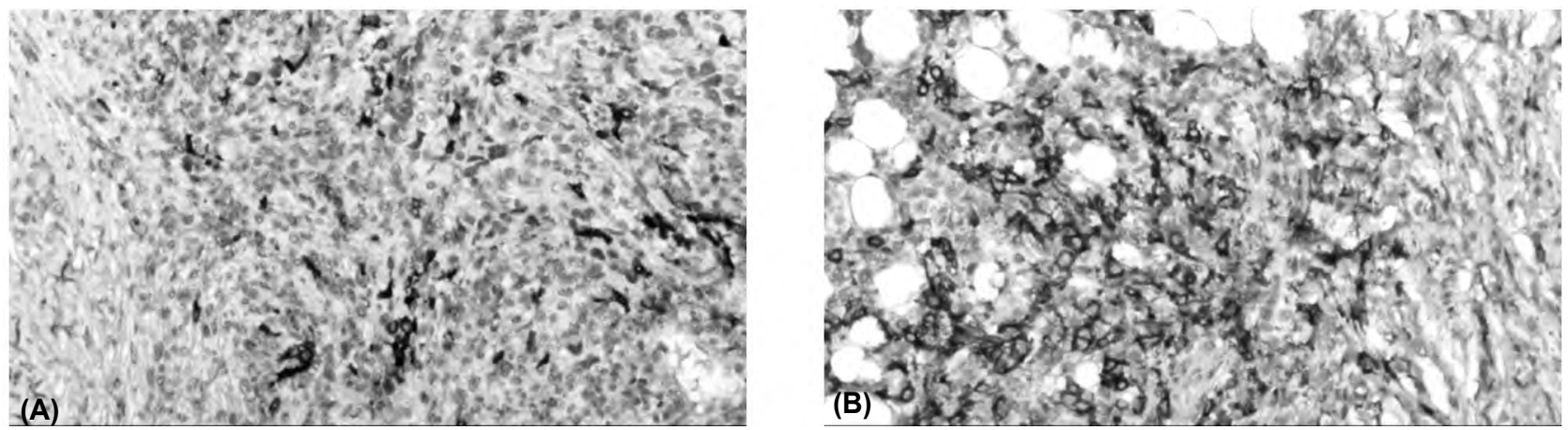

Fig. (7): CD44 stain in two cases, (a) X100 and (b) X100.

\section{Discussion}

Kiricuta and Popescu (1973) first described harvesting omental flaps through a laparotomy that was associated with several complications and disadvantages [15]. It was not until earlier in the millennium that the introduction of laparoscopy as a technique for harvesting the flap and that the number of cases started to increase [8]. The advantages of laparoscopy results in minimizing the effects of dissection on the donor site, the incisions visible to the patients and their scars, a decreased operative time, and associated complications $[16,17]$

One of the different modalities of volume replacement in breast oncoplastic surgery is the use of omental pedicled flap [18]. Like other autologous flaps, this flap serves well for patients who might refuse or cannot afford the insertion of prosthetic materials in their bodies [19].

In the review of the literature agreement was concluded on advantageous properties of the omentum in terms of its malleability to any shape. Advantages were identified for the use of the omental flap in terms of outcome, mainly its superior aesthetics, its availability in all patients, the omentum's rich blood supply that supports healing and its immunogenic properties that prevent infections $[20,21]$

Two questions should be answered. First, bringing an intraabdominal organ into a subcutaneous position where it would be exposed to external radiation that would modulate its properties. Second, bringing an innocent intraabdominal organ into direct contact with cancer bed, would carry a potential risk of transporting malignancy into the abdomen. The fate of that omental flap that was transposed into the breast is not well studied. Very few reports are available in the literature but not covering all the aspects. In this study we tried to find out the final outcome of the flap based on studying its vascularity (by Doppler), shape (by imaging studies) and the potential immune function or risk factor for recurrence (by Histopathology).

A total number of 10 female patients eligible for immediate breast reconstruction with volume replacement using laparoscopically harvested omental flap following breast conservative surgery were included in this study.

The patients age ranged from 26 to 72 years old with mean age $44.7 \pm 12.21$. Zaha and Inamine (2010) published a large study examining laparoscopically harvested omental flaps among 96 women. They evaluated a relatively older group of women (mean age 49 years) [17]. Khater (2013) published a study for evaluation of pedicled omental flap delivered through a minilaparotomy for immediate breast reconstruction in obese patients for 24 patients with mean age of 57.54 years. 22 However, The age of the patients has no value in the final assessment of either the oncologic safety or the aesthetic outcome of the procedure [23] Nevertheless, we observed that the patients felt satisfied with preserving the breast whatever its residual shape or contour.

The viability of the omental flap can be studied intraoperatively through laser Doppler flowmetry [24] . Or postoperatively by exposing a small part of the flap through the skin [16]. In the present study, viability of the omental flap was assessed postoperatively by Doppler, which revealed partial infarction and degeneration in $20 \%$ of the studied cases, probably due to the effect of radiation received postoperatively. That would be attributed to the improper mapping and improper adjustment of the radiation dosage, as Trombetta et al. (2010) reported in their study. [25] Costa et al (2011) reported an increase in size of free flaps up to 6 months postoperatively, which was attributed to the temporary ischemia. [26] Khater (2013) in his study noted that flap survival was excellent, with only a single case of partial necrosis (4\%) [22] This high discrepancy among findings regarding 
the viability of the flap could be related to the difference in patients' response to radiation dosage improperly adjusted.

Regarding mammography with complementary ultrasonography, $40 \%$ of cases had mixed fatty glandular density, $20 \%$ were fatty, $20 \%$ were micronodular, whereas $20 \%$ were mixed fibrofatty. No masses were detected in $50 \%$ of the studied cases. No calcification was detected in any case during the follow-up period. One case had a small cyst, which was proved by Histopathology to have a benign nature. Nodules were detected in $40 \%$ of cases due to partial fibrosis from fat necrosis and Tru-Cut needle biopsy and Histopathological study proved their benign nature. That is probably due to the effect of external radiation taken postoperatively because the omental tissue tolerance to radiation is different from the breast tissue $[25,27,28]$ No recurrence of tumor was detected as proved by histopathology.

Histopathological exam detected various degrees of inflammatory reaction, it was minimal in $50 \%$ of the studied cases. The immune system has the power to modulate the damage effect of radiation on normal and tumor tissue. It can contribute to cancer cure, on the other hand it can influence acute and late radiation side effects, which in many ways resemble acute and chronic inflammatory disease states [29]. CD8, an indicator of the presence of T-Killer cells, percentages were somehow related to the degree of inflammatory reaction found, mild presence was found in 50\% of cases and moderate presence was found in $40 \%$ of cases. These findings are compatible with the innate property of the omentum [30].

Fat necrosis was obvious in the omental flap. It was detected to be extensive in $50 \%$ of the studied cases. This was probably due to the omental exposure to radiation extraabdominaly leading to partial infarction and degeneration $[25,27,28]$. Guan $\mathrm{D}$ et al. (2015) observed fat necrotic nodule in $12.5 \%$ of cases among 24 cases with laparoscopic harvested omental flap [31]. Zaha et al. (2017) observed fat necrosis occurred in $5.2 \%$ of patients. 32 The high incidence of fat necrosis in the present study may be related to increased response to postoperative radiation. This adverse effect was reported by Garsa et al. (2013) in cases receiving interstitial brachytherapy. They also reported that fat necrosis is associated with worse qualitative and quantitative cosmetic outcomes [33]. Therefore, minimizing exposure volumes, may decrease the incidence of fat necrosis and improve cosmesis.
In the present study, the degree of fibrosis detected was mostly dense during the follow-up period in $50 \%$ of the studied cases. Some studies suggested a genetic factor for excessive fibrotic response to radiation. Grossberg et al., conducted a study in 2018 aiming for validation of a genomic marker for radiation fibrosis. The $\mathrm{C}-509 \mathrm{~T}$ allele in transforming growth factor 31 (TGFB 1 ) is a key determinant of breast fibrosis risk. Assessing TGFB 1 genotype may facilitate a more personalized approach to locoregional treatment decisions in breast cancer [34]

In the present study, vasculitis was detected in $30 \%$ of the studied cases. Most probably due to the innate property of the omentum to produce capillary ingrowth, also would be as an inflammatory response to external radiation $[\mathbf{1 3 , 3 5 , 3 6 ]}$. No studies in the literature reported vasculitis in the omental flap used for immediate breast reconstruction following breast conservative surgery.

Over the short period of follow-up in the present study, no recurrence of malignancy could be detected in any of the studied cases. Moran et al., in a recent meta-analysis of 33 studies including 28,162 patients who underwent breast conservative surgery and omental flap reconstruction for stage I and II invasive breast cancer revealed a median prevalence of ipsilateral breast tumor recurrence of $5.3 \%$ in a median follow-up period of 79.2 months [37]. Compared with this meta-analysis, Zaha et al. (2017) reported lower local recurrence rate with a longer median follow-up period of 90 months, which suggests the oncological safety of the laparoscopically harvested omental flap procedure [32]

In the present study, we used CD31 marker to measure angiogenesis in the omental flap. There was an increase in the number of vessels noted suggesting neo-angiogenesis. We reported mild increase in $20 \%$ of cases, moderate increase in $40 \%$ of cases and severe increase in $40 \%$ of cases. This stain is an indicator for vasculo-endothelial cells. The higher was the vasculo-endothelial cells found, the higher the degree of fibrosis on Histopathological study.

CD44 stain is a marker for stem cells. In the present study, we reported 2 positive cases out of $10(20 \%)$. No studies regarding this point were found in the literature. However, some studies reported CD44 as a marker of breast cancer cells. 38,39 Other studies used it as a prognostic factor for breast cancer. Whenever it is expressed in high percentage in the breast cancer it worsens the 
prognosis [40]. Consequently, increased expression of CD44 in the omentum would be considered as a predictor of recurrence.

\section{Conclusion:}

Tumor should be completely eradicated before the use of omental flap as a volume replacement after breast conservative surgery. The laparoscopically harvested omental flap had a promising oncological safety during the follow up. The omental flap can achieve a good cosmetic outcome in breast reconstruction after breast conservative surgery. In spite of the fibrosis and nodulation found, no change was observed in the shape or contour of the breast. Any nodule detected during the follow up should be biopsied and examined histopathologically. The inflammatory reaction and enhanced local immunity by the omentum is not studied as a possible preventive factor for recurrence. Vasculitis due to angiogenesis and inflammatory reaction is not studied well as a potential enhancing factor for recurrence. The presence of CD44 in the omental flap is not studied as it would potentiate the recurrence of breast cancer.

\section{Recommendations:}

Long term follow-up is essential to see whether the omental flap could be a barrier against the recurrence of tumor due to its immunological function, or it can enhance the recurrence due to its angiogenetic capabilities together with production of stem cells in some cases.

\section{Limitations:}

This is a single-centre experience and represents a limited number of patients.

\section{Financial support and sponsorship:}

Nil.

\section{Conflicts of interest:}

There are no conflicts of interest.

\section{Authors' contributions}

All authors had equal role in design, work, statistical analysis and manuscript writing.

\section{References}

1- FISHER B., ANDERSON S., BRYANT J., et al.: TwentyYear Follow-up of a Randomized Trial Comparing Total Mastectomy, Lumpectomy, and Lumpectomy plus Irradiation for the Treatment of Invasive Breast Cancer. N. Engl. J. Med., 347 (16): 1233-1241, 2002.

2- VERONESI U., CASCINELLI N., MARIANI L., et al.: Twenty-Year Follow-up of a Randomized Study Comparing Breast-Conserving Surgery with Radical Mastectomy for Early Breast Cancer. N. Engl. J. Med., 347 (16): $1227-$ 1232,2002

3- ELDER E.E., BRANDBERG Y., BJÖRKLUND T., et al.: Quality of life and patient satisfaction in breast cancer patients after immediate breast reconstruction: A prospective study. Breast, 14 (3): 201-208, 2005.

4- JAHKOLA T., ASKO-SELJAVAARA S. and VON SMITTEN K.: Immediate Breast Reconstruction. Scand J. Surg., 92 (4): 249-256, 2003.

5- CHRISTENSEN B.O., OVERGAARD J., KETTNER L.O., et al.: Long-term evaluation of postmastectomy breast reconstruction. Acta. Oncol., 50 (7): 1053-1061, 2011.

6- KIRICUTA I.: The use of the great omentum in the surgery of breast cancer. Presse Med., 71: 15-17, 1963.

7- ARNOLD P.G., HARTRAMPF C.R. and JURKIEWIEZ M.J.: One-stage reconstruction of the breast, using the transposed greater omentum: Case report. Plast. Reconstr. Surg., 57 (4): 520-522, 1976.

8- SALTZ R., STOWERS R., SMITH M., et al.: Laparoscopically harvested omental free flap to cover a large soft tissue defect. Ann. Surg., 217 (5): 542-547, 1993.

9- DOS SANTOS COSTA S., BLOTTA R.M., MARIANO M.B., et al.: Aesthetic improvements in Poland's syndrome treatment with omentum flap. Aesthetic Plast. Surg., 34 (5): 634-639, 2010.

10- LITBARG N.O., GUDEHITHLU K.P., SETHUPATHI P., et al.: Activated omentum becomes rich in factors that promote healing and tissue regeneration. Cell Tissue Res., 328 (3): 487-497, 2007.

11- SINGH A.K., PATEL J., LITBARG N.O., et al.: Stromal cells cultured from omentum express pluripotent markers, produce high amounts of VEGF, and engraft to injured sites. Cell Tissue Res., 332 (1): 81-88, 2008.

12- SINGH A.K., PANCHOLI N., PATEL J., et al.: Omentum facilitates liver regeneration. World J. Gastroenterol., 15 (9): 1057-1064, 2009.

13- GARCÍA-GÓMEZ I., GOLDSMITH H.S., ANGULO J., et al.: Angiogenic capacity of human omental stem cells. Neurol. Res., 27 (8): 807-811, 2005.

14- SHAH S., LOWERY E., BRAUN R.K., et al.: Cellular basis of tissue regeneration by omentum. PLoS One, 7 (6): e38368, 2012.

15- KIRICUTA I. and POPESCU V.: Breast plasties with the omentum magnum in prethoracic transposition. Chir. Plast., 2 (1): 47-56, 1973.

16- JIMENEZ A.G., ST GERMAIN P., SIROIS M. and HATHEWAY M.L.R.: Free omental flap for skin-sparing breast reconstruction harvested laparoscopically. Plast. Reconstr. Surg., 110: 545-551, 2002

17- ZAHA H. and INAMINE S.: Laparoscopically harvested omental flap: Results for 96 patients. Surg Endosc Other Interv. Tech., 24 (1): 103-107, 2010.

18- BOSTWICK J., VASCONEZ L.O. and JURKIEWICZ M.J.: Breast reconstruction after a radical mastectomy. Plast. Reconstr. Surg., 61 (5): 682-693, 1978.

19- EROL O.O. and SPIRA M.: Reconstructing the breast mound employing a secondary island omental skin flap. Plast. Reconstr. Surg., 86 (3): 510-518, 1990. 
20- MATROS E. and DISA J.: Uncommon Flaps for Chest Wall Reconstruction. Semin Plast. Surg., 25 (01): 055059, 2011.

21- HULTMAN C.S., CULBERTSON J.H., JONES G.E., et al.: Thoracic reconstruction with the omentum: Indications, complications, and results. Ann. Plast. Surg., 46 (3): 242249, 2001.

22- KHATER A.: Evaluation of Pedicled Omental Flap Delivered through a Minilaparotomy for Immediate Breast Reconstruction in Obese Patients. Aesthetic Plast. Surg., 37 (6): 1140-1145, 2013.

23- TOURNIEUX T.T..: Predictive factors of good aesthetic results in conservative surgery for breast cancer. Rev. Bras. Cir. Plást., 27: 37-48, 2012.

24- OBAID S.I. and MORRIS D.J.: Laser Doppler perfusion imager use in incisional hernia repair following omental breast reconstruction. Plast. Reconstr. Surg., 109 (6): 2006-2008, 2002.

25- TROMBETTA M., VALAKH V., JULIAN T.B., et al.: Mammary fat necrosis following radiotherapy in the conservative management of localized breast cancer: Does it matter? Radiother. Oncol., 97 (1): 92-94, 2010.

26- COSTA S.S., BLOTTA R.M., MEURER L., et al.: Adipocyte morphometric evaluation and angiogenesis in the omentum transposed to the breast: a preliminary study. Clinics., 66 (2): 307-3 12, 2011.

27- OWEN J.R., ASHTON A., BLISS J.M., et al.: Effect of radiotherapy fraction size on tumour control in patients with early-stage breast cancer after local tumour excision: Long-term results of a randomised trial. Lancet Oncol., 7 (6): 467-471, 2006.

28- WHELAN T.J., PIGNOL J-P., JULIAN J., et al.: LongTerm Results of Hypofractionated Radiation Therapy for Breast Cancer. N. Engl. J. Med., 362: 513-520, 2010.

29- SCHAUE D., MICEWICZ E.D., RATIKAN J.A., et al.: Radiation and inflammation. Semin. Radiat. Oncol., 25 (1): 4-10, 2015.

30- BEELEN R.H. : The greater omentum: Physiology and immunological concepts. Neth. J. Surg., 43 (5): 145-149, 1991.
31- GUAN D., LIN H., LV Z., et al.: The oncoplastic breast surgery with pedicled omental flap harvested by laparoscopy: Initial experiences from China. World J. Surg. Oncol., 13 (1): 95, 2015.

32- ZAHA H., ABE N., SAGAWA N., et al.: Oncoplastic surgery with omental flap reconstruction: A study of 200 cases. Breast Cancer Res. Treat., 162 (2): 267-274, 2017.

33- GARSA A.A., FERRARO D.J., DeWEES T., et al.: Analysis of fat necrosis after adjuvant high-dose-rate interstitial brachytherapy for early stage breast cancer. Brachytherapy, 12 (2): 99-106, 2013.

34- GROSSBERG A.J., LEI X., XU T., et al.: Association of Transforming Growth Factor [3 Polymorphism C-509T With Radiation-Induced Fibrosis Among Patients With Early-Stage Breast Cancer. JAMA Oncol., 2018

35- CARTIER R., BRUNETTE I., HASHIMOTO K., et al.: Angiogenic factor: A possible mechanism for neovascularization produced by omental pedicles. J. Thorac. Cardiovasc. Surg., 99 (2): 264-268, 1990.

36- SIGRIST S., MECHINE-NEUVILLE A., MANDES K., et al.: Induction of angiogenesis in omentum with vascular endothelial growth factor: Influence on the viability of encapsulated rat pancreatic islets during transplantation. J. Vasc. Res., 40 (4): 359-367, 2003.

37- MORAN M.S., SCHNITT S.J., GIULIANO A.E., et al.: Society of Surgical Oncology-American Society for Radiation Oncology consensus guideline on margins for breast-conserving surgery with whole-breast irradiation in stages I and II invasive breast cancer. Int. J. Radiat. Oncol. Biol. Phys., 88 (3): 553-564, 2014.

38- SHIPITSIN M., CAMPBELL L.L., ARGANI P., et al.: Article Molecular Definition of Breast Tumor Heterogeneity. Cancer Cell., 11 (March): 259-273, 2007.

39- CHEKHUN S.V., ZADVORNY T.V., TYMOVSKA Y.O., et al.: CD44+/CD24- Markers of cancer stem cells in patients with breast cancer of different molecular subtypes. Exp. Oncol., 37 (1): 58-63, 2015.

40- ABRAHAM B.K., FRITZ P., McCLELLAN M., et al.: Prevalence of CD44+/CD24-/low cells in breast cancer may not be associated with clinical outcome but may favor distant metastasis. Clin. Cancer Res., 11: 1154$1159,2005$. 


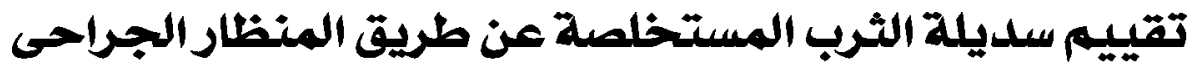

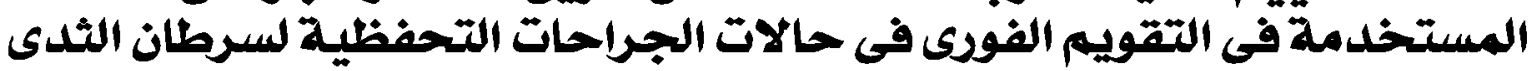

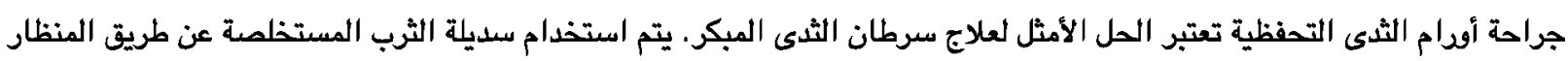

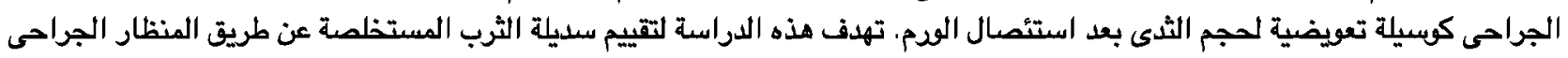

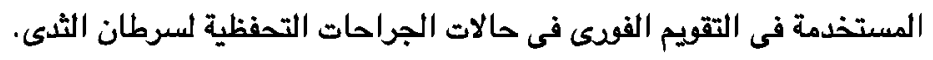

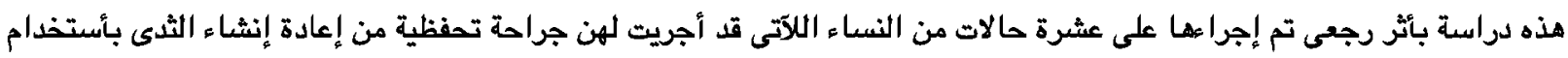

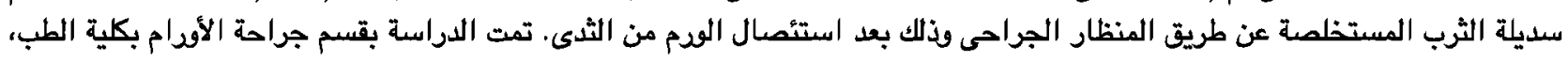

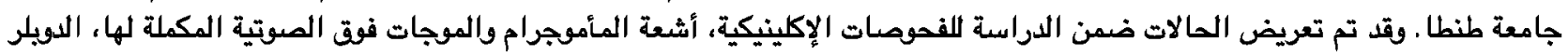
وتحليل الأنسجة لتقييم سديلة الثرب المستخدمة.

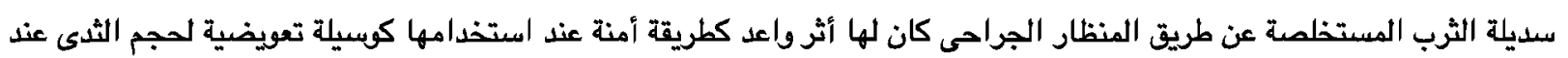

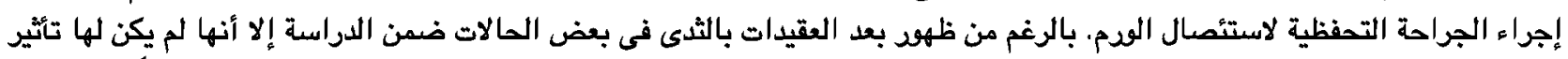

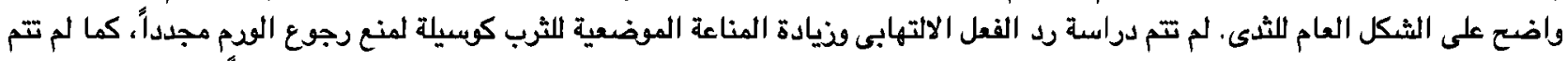

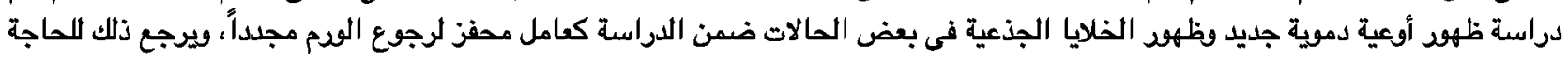
لعدد أكبر من الحالات ومدة دراسة أطول. 